\title{
Students' Experiences of Autonomy, Competence, Social Relatedness and Interest Within a CSCL Environment in Vocational Education: The Case of Commerce and Business Administration
}

\author{
Alexander Minnaert • Monique Boekaerts • \\ Cornelis de Brabander • \\ Marie-Christine Opdenakker
}

Received: 9 December 2009 / Accepted: 29 March 2011 /

Published online: 12 April 2011

C The Author(s) 2011. This article is published with open access at Springerlink.com

\begin{abstract}
To prepare students for effective workplace learning, it is necessary to have insight into the contextual characteristics that affect students' developing interest. Aiming at students to become selfregulated learners, teachers should act as mindful coaches, encouraging their students to monitor the quality of collaborative group work. A field study was conducted within the context of a Computer Supported Collaborative Learning (CSCL) project fostering self-regulated learning. Students and teachers made use of an electronic instrument that assessed and visualised students' experiences of the quality of group learning over time. 137 vocational students in commerce and business administration participated in a 6 months project requiring to work in small learning groups. A SEM model, based on self-determination theory, fitted the data quite well. Perceived autonomy, competence, and social relatedness seemed to be good predictors of students' situational interest. Qualitative interview data revealed not only the added value of process-oriented reflection and within-group discussion, but also some shortcomings concerning the effectiveness of (implementing) CSCL.
\end{abstract}

Keywords Computer Supported Collaborative Learning · Workplace learning · Vocational education · Self-determination theory Interest

\footnotetext{
A. Minnaert $(\bowtie) \cdot$ M.-C. Opdenakker

Department of Educational Sciences, University of Groningen, Grote Rozenstraat 38,

Groningen 9712 TJ, The Netherlands

e-mail: a.e.m.g.minnaert@rug.nl

M. Boekaerts $\cdot$ C. de Brabander

Centre for the Study of Education and Instruction, Leiden University, Leiden, The Netherlands
} 


\section{Collaborative Learning and ICT}

The integration of collaborative learning and Information \& Communication Technology (ICT) within the context of constructivist educational settings yields promising opportunities to design powerful learning environments aiming at knowledge sharing, knowledge construction, knowledge building, and selfregulation (Martens, Bastiaens \& Kirschner, 2007). Empirical evidence demonstrating the effectiveness of collaborative learning (Johnson \& Johnson, 2009), theoretical frameworks stressing the viewpoint that learning is a process driven by both social and cognitive factors (Minnaert \& Vermunt, 2006), and the urge of society calling for teamwork in combination with ICT led to the upsurge of different forms of collaborative learning in all educational levels (Sluijsmans \& Strijbos, 2010). The effects of ICT, however, depend not only on the equipment, but above all on the pedagogical and didactical implementation of technology (Lehtinen, 2003; Martens, Bastiaens \& Kirschner, 2007). In the early years of ICT supported learning, one of the major worries among teachers and educators was the omission of specifications to promote social interaction and collaboration (Lehtinen, 2003). During the last two decades, the use of ICT in education has been focused explicitly on the possibilities to facilitate social interaction and collaboration between teachers and students as well as among students (Koschmann, Hall \& Miyake, 2002). During the last few years, a substantial increase in the use of technology based learning environments has been noticed in education, workplace learning, and vocational education and training (VET), often neglecting the beliefs, learning approaches, and emotions in students' behaviour (see Vuorela \& Nummenmaa, 2004).

The rationale of Computer Supported Collaborative Learning (CSCL) in teaching and learning environments is amply documented (for a review, see Lehtinen, 2003) and two major issues are put forward in relation to the effectiveness of CSCL environments. First, the crux of persons working in collaborative settings is the externalization of ideas, perspectives, and conceptions to others. Inner thoughts and processes are transformed into an externalised form that is accessible and understandable for others. Pea (1994) showed that CSCL acts as a mediating tool to facilitate this transformation process both in distance and face-to-face education in a very active and mindful way. Several researchers (Dillenbourg \& Traum, 1999; Järvelä, Bonk, Lehtinen \& Lehti, 1999) described the teaching-learning process as a very complex situation containing a network of actors, each having (personal) goals, beliefs, and interpretations that might influence the knowledge, beliefs, and skills of other members of the group. Mutual understanding, i.e. understanding other group members thinking, inquiring, and reflection, has been identified as crucial in developing effective CSCL applications. Consequently, CSCL environments should be evaluated on the dimension of shared understanding.

Second, as CSCL group members participate in the construction of a joint product, they participate in a small community of learners aiming at knowledge building and self-regulation. As King (1998) remarked, this scenario requires not only highly intensive and collaborative activities, but also reciprocity and interdependence between the group members in order to meet the conditions for effective collaboration. Several obstacles may occur and call for self-regulated or external regulation (Vauras, Iiskala, Kajamies, Kinnunen \& Lehtinen, 2003). For 
example, when students are confronted with difficult content-related obstacles or with a lack of learner autonomy, when problems arise within the group that might harm reciprocity and interdependence. We are confronted here with a paradox. On the one hand, the coach has to find a subtle balance between scaffolding intensive, active, and collaborative activities and being careful not to intervene too much. On the other hand, the CSCL environments provides coaches with a lot of information about the group (learning) process and progress. Therefore, teachers need to offer opportunities for students where they can learn to monitor for and reflect on their own and others' (social) learning conceptions and experiences. This monitoring and reflection process is as an absolute prerequisite within the context of improving selfregulated learning in CSCL environments.

Several researchers argued that the quality of collaboration and group responsibility is open to discussion (see Anderson, 1994; Vedder \& Veendrick, 2003), particularly in the first stages of a group project. Disruptive influences, such as working more independently than collaboratively, lower status and minority students participating less in cognitively challenging activities, play a detrimental role on the outcomes of collaborative learning. Social network analysis studies clearly demonstrate an unequal participation in CSCL processes (Cho, Stefanone \& Gray, 2002). Bennett and Dunne (1991) showed that students do not always spontaneously reflect on their own learning processes and they do not always clarify their own or their peers' understandings. More recently, in the study of Virtanen, Tynjälä and Collin (2009) on workplace learning among Finnish vocational students, it was found that the mean value of working alone was somewhat higher than that of social learning. Besides, students of commerce and administration gave significant lower scores for social learning compared to students of social sciences and health care.

Based on an overview of the literature, Ewing and Miller (2002) postulated a composite framework to evaluate CSCL environments. They identified five key features, namely (1) increasing learner autonomy by taking learners responsibility and accountability into account, (2) enhancing collaborative learning as interaction takes place in small peer groups or learning teams, (3) going beyond mere knowledge transmission aiming at knowledge building by means of communication and dynamic learning processes, (4) promoting personal task involvement in line with the goals of the learner, and (5) supporting (ICT) learning skills and the development of self-regulation. Researchers have amply documented that indicators of the quality of experience in learning settings are closely related to the level of being interested in the actual learning task (see e.g., Hidi \& Renninger, 2006; Krapp, 1999; Mitchell, 1993; Renninger, Hidi \& Krapp, 1992; Schiefele, 1991). A key question is whether students are aware of their maintained and emerging interest in an area of study and whether they have insight into the conditions that facilitate or impede their interest development (Debnath, Tandon \& Pointer, 2007). This focus is rather unexplored within the area of a CSCL context. Besides, it is important that students learn to share their process- and product-oriented experiences with their peers and learn to interpret feedback (Lindblom-Ylänne \& Pihlajamaki, 2003). Feedback is, however, too often product-oriented and hardly focused on the ongoing learning process. Boekaerts (1997) argued that little attention has yet been focused on process-oriented feedback aiming at students' competency to reflect on and to regulate motivational, social, and emotional processes before, during, and after peer- 
mediated learning activities. At present, educational practice is handicapped by a lack of instruments that register students' maintained situational and emerging individual interest. In the next section, we will argue that it is crucially important that students are invited to reflect on the quality of the learning process in terms of the situational interest it engenders and on the type of constraints and affordances that they meet in a technology based learning environment.

\section{Self-Determination and Students' Developing Interest in a CSCL Project}

The concept of psychological needs facilitates the specification of the conditions that are favourable or unfavourable for the development of (situational and individual) interest. There is ample evidence from self-determination theory (see Grolnick \& Ryan, 1989; Deci et al. 1991; Connell \& Wellborn, 1991) that a learning environment that satisfies students' need for autonomy, competence, and social relatedness is a necessary condition for learners to be self-determined and selfregulating. Learning environments that provide students with opportunities to satisfy their basic psychological needs affect their intrinsic motivation and autonomous selfregulation, and in turn, the quality of their performance. By contrast, learning conditions that tend to promote controlling forms of extrinsic motivation often lead to relatively poor functioning during task engagement (see Ryan \& Deci, 2000). Hence, the connection between students' needs for autonomy, competence, and social relatedness and students' experience of situational interest is of importance in self-determined learning (see Lewalter \& Krapp, 2004). Once the situational interest is triggered, it remains doubtful whether this situational interest remains maintained or not (Hidi \& Renninger, 2006).

In self-determination theory (Deci \& Ryan, 1985; Ryan \& Deci, 2000), researchers have typically argued that an activity is self-determined when the person perceives the locus of causality as internal to his or her Self. When others control an activity, the regulatory process is compliance (or even defiance in some cases) and the perceived locus of causality is external to the self. Self-determination theory has specified a set of three innate psychological needs that are relevant to intrinsic and extrinsic motivation, and as such also to developing self-regulation: the need for competence, relatedness, and autonomy. The need for competence involves understanding how to attain various external and internal outcomes and being self-efficacious in performing the requisite actions. The need for social relatedness involves developing secure and satisfying connections with others in one's social milieu. The need for autonomy refers to freedom of action, mainly being self-initiating and self-regulating one's own actions (Deci, Vallerand, Pelletier \& Ryan, 1991).

The present research takes as its focus the examination of the three basic psychological needs and links them to students' developing situational interest. A number of authors (see e.g., Renninger et al. 1992; Schiefele, 1991, 2001; Schraw \& Lehman, 2001) have demonstrated the relationship between interest and various indicators of academic learning (e.g. achievement, text learning, depth of learning) and have emphasised the relationship between interest and psychological needs (see e.g., Alexander \& Wade, 2000; Krapp, 2002; Lewalter \& Krapp, 2004). As situational interest is more obvious for teachers to discern in collaborative learning, 
we focus on the development of interest over time. In the context of self-determined group work in a CSCL environment (see Fig. 1), we therefore hypothesise that the students' situational interest in a group project taps - to a large extent - their underlying need satisfaction. This calls for a recording method that can capture induced motivational states quasi real-time. When recording motivational states close in time to the event(s) that elicited them, it is less likely that students will have forgotten their specific thoughts and feelings about the learning situation.

As a first step to capture students' psychological needs and interest on-line, Boekaerts and Minnaert (2003) constructed a paper-and-pencil version of the Quality of Working in Groups Instrument and registered students' feelings of autonomy, competence, and social relatedness during successive sessions of working on a group project, as well as their interest in the project. It was predicted and found that feelings of competence, autonomy, and social relatedness fluctuate during the course of the group project and that these aspects of a student's basic psychological needs have a strong impact on the interest they express in the project during its successive stages. Based on these results, we theorised that information about students' reported psychological needs can be collected at the individual level, then aggregated at the group level and fed back to the respective groups. This feedback process would allow each group of students to discuss the nature of their task engagement and initiate behaviour to counteract the perception of low autonomy, low competence, or low social relatedness.

The electronic version of the Quality of Working in Groups Instrument (Minnaert, Boekaerts \& de Brabander, 2007) was constructed after examining relevant instruments and several try-outs with the paper-and-pencil version in vocational education. The advantage of a computer-based instrument is that students can get behind a computer screen and complete the questionnaire whenever they feel like sharing information about their interest and psychological need states with their peers or their teacher(s) and/or want to get feedback on their developing interest. The electronic version was adapted for reflective feedback purposes by providing process-oriented, graphical output as well as a digital interface. The instructions encourage students to inspect their own graphical curves for autonomy, competence, social relatedness, and interest over time. They are also invited to compare their own graph with those of the other group members, aiming at reciprocity and interdependence between the group members. Students are explicitly requested to reflect on this information and to discuss the process-oriented feedback within the project group.

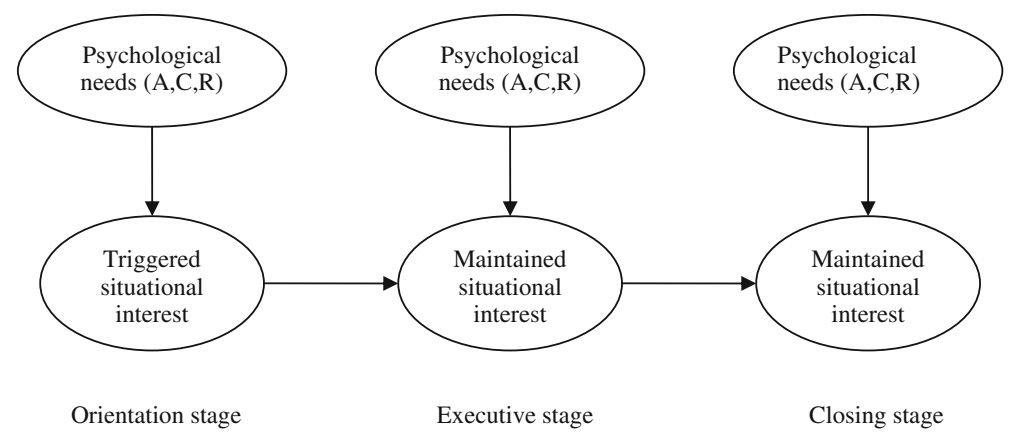

Fig. 1 Theoretical model of developing interest in coursework within a CSCL project. $A$ Autonomy, $C$ Competence, $R$ Social Relatedness 
It was our intention that these graphical representations would hint - in a timely manner at obstacles in the functioning of the project groups. Students are also encouraged to use the digital interface facility to communicate with their teachers/coaches. These coaches had access to the longitudinal data of the students they were mentoring. We hoped that students would gradually become aware of imminent and recurrent impediments in group learning that would call for teacher guidance and feedback.

Based on observations and earlier studies in vocational education (Minnaert, Boekaerts \& De Brabander, 2007), we predicted that students' sense of autonomy (feeling free to initiate and regulate their own actions) during group work is intricately linked to their understanding of how to solve a problem or complete an assignment, and to being self-efficacious in performing the necessary and sufficient actions (competence), as well as to their ability to establish satisfying connections with members of the group (social relatedness). Another prediction pertains to interest expressed in the project. It was hypothesised that perceived autonomy, competence, and social relatedness jointly influence students' expression of situational interest in the group project. Besides, it was hypothesised that students and coaches, who worked with the Quality of Working in Groups Instrument, would become aware of their changing interest in the group project and in the underlying reasons for a decline or increase in students' interest over time, and - consequently - become more aware of the (factors influencing the) quality of collaboration in a group project.

\section{Method}

\section{Subjects}

Participants were 137 students in secondary vocational education. These students were between 15 and 18 years old at the time of data collection and studied commerce and business administration. All students were involved in an educational innovation project that fostered more self-regulated learning in students and more process-oriented teaching and coaching in teachers. Students came from different classes, and from different social and cultural backgrounds. They took part in a compulsory course on the structure and organization of small-scale business concerns. In fact, this course required them to integrate and apply knowledge from courses in different subject-matter areas. This integrative course was set up by teachers from different content areas and lasted 7 months. Students were asked to work in small learning groups (of 4-5 students) on a self-selected topic that fitted within the scope and aims of the course. Students worked in a collaborative manner, part of the time on-line (making use of the interface tools) and part of the time faceto-face. The participating teachers acted as coaches.

At the end of the project, ten students and two teachers were randomly chosen to participate in a semi-structured group interview about the benefits and shortcomings of Quality of Working in Groups Instrument. Each of the participants was requested to write down two benefits and two shortcomings of the CSCL project. After making an inventory of all answers, we asked the participants (in two subgroups) to prioritise the benefits and shortcomings separately and to articulate the grounding for this order. Additionally, the participants were enquired to articulate the stage(s) in which 
this benefit or shortcoming should be situated. Besides, the participants were fostered to explain stage by stage how we should interpret the relatedness of autonomy, competence, social relatedness and interest.

\section{Instrument and Measures}

The electronic version (Minnaert, Boekaerts \& de Brabander, 2007) required students to complete ten bipolar self-report items with two opposing statements located at either end of a seven-point Likert scale. Students completed these items online halfway through or at the end of the workplace learning day. All together, these items assessed students' psychological needs, namely their experiences of autonomy (2), social relatedness combined with the degree of responsibility for learning in groups (4), competence (2), and interest in the group project (2). The exact wording of the items can be found in the appendix. Students who indicate high agreement with a negative statement (i.e. low feelings of autonomy, competence, social relatedness, and interest, respectively) receive a score of one whereas high agreement with a positive statement receives a score of seven. Cronbach's alpha were calculated to estimate the internal reliability of each scale separately. Over time, mean reliability was .81 for autonomy, .70 for competence, .87 for social relatedness, and .85 for interest. Taken into account the number of items per scale, these reliability coefficients are quite satisfying on group level (see Cortina, 1993). In addition, profile reliability of the 4 scales was .71, which is more than sufficient for further analysis. Lienert and Raatz (1994) mentioned a coefficient of .50 as the lower limit of sufficiency.

Completing the questionnaire requires students to reflect upon the quality of the group learning process, as they currently perceive it, focusing on their psychological need states. As soon as they complete the questionnaire, four colourful curves are visualised, depicting the three basic psychological needs as well as their developing interest in the group project. Students are able to inspect their own curves for autonomy, competence, social relatedness, and interest over time, as well as those of their group (data aggregated at the group level). In other words, individual information can be compared and contrasted with visual information provided at the group level. Students are explicitly requested to reflect on this information and to discuss the process-oriented feedback within the project group. A digital interface is provided to communicate with the teachers. Teachers are explicitly asked to inspect the graphs regularly and answer the student's queries. Note, that students are not communicating directly with the researchers. Students complete the instrument primarily to express their current psychological experiences and reflect on them, but also to get feedback in relation to their own past experiences and that of their peers.

\section{Procedure}

Students were working on a self-chosen CSCL project during 1 day a week for two semesters. In order to built up the competences of all the group members, each student had to collect and read additional information about aspects of the selected project (e.g. about small-scale business concerns, or about the organisation of a cultural event), visit relevant institutions, and discuss the collected information with group members to build up a common knowledge base, but also to air their opinions 
and to defend their arguments. Students had to set their own goals and monitor their progress towards these goals. In order to help the groups to structure and organise the group learning experiences and the preparation and presentation of the group paper, teachers acted as coaches. Each group had to choose a leader, whose task it was to enhance and monitor the communication among the group members and interact with the other groups and with the coach(es). Direct teaching was organised only if students explicitly asked for it. Students were requested to complete the Quality of Working in Groups Instrument once a week during their project day.

All teachers involved in the educational innovation project received oral and written information about (1) the theoretical framework behind the Quality of Working in Groups Instrument, (2) the characteristics and possibilities of the on-line version, (3) their role as coaches (i.e., to enhance reflection on the (social) learning process by means of the graphical output and to foster discussion of this process-oriented feedback within the project groups). It was assumed that the information about individual students' interest in the project as well as information about their psychological need states would be used by the participating teachers to structure the coaching process. Teachers were requested to distinguish between three stages in the course: the orientation stage (when their students were making a plan of action), the executive stage (when students were bringing the plan into action and had to monitor the process in order to realise the intended plan), and the closing stage (when students were writing up their paper and preparing for oral presentation of the project to the other groups and the teachers). The data were deliberately aggregated into five measurement points, namely one in the orientation stage, three in the executive stage (one at the start, one in the middle, and one at the end of this stage), and one in the closing stage. These five measurement moments reflect the different stages teachers are familiarised with in project education, even before the implementation of this CSCL project.

\section{Analyses}

To investigate the relationship between autonomy, competence, social relatedness, and interest, Pearson correlations were calculated per measurement moment. SEM (Structural Equation Modelling) was conducted to examine the longitudinal effect patterns of psychological needs on situational interest over time, taking into account the already triggered situational interest in the previous stage of the CSCL project and taking into account the patterns of correlations between autonomy, competence, and social relatedness. This way of modelling allowed us to estimate the amount of variance explained in interest per measurement moment. SEM was conducted on the variancecovariance matrix and estimated by the Maximum Likelihood method of estimation.

\section{Results}

The Relationship Between Autonomy, Competence, Social Relatedness, and Interest Over time

The correlations between the three psychological needs experiences (i.e., autonomy, competence, and social relatedness), and between these experiences and developing 
interest are shown in Table 1, separately for each measurement moment. Close inspection of the patterns of correlations revealed that, as predicted, autonomy is associated with both competence and social relatedness, as well as with interest in all stages of the project. It is noteworthy that the correlations between autonomy on the one hand and competence and social relatedness on the other were - although statistically significant-modest in the first stage of the project (.22 and .23), but increased in the following stages (.34-.62). The associations between competence and social relatedness were almost absent in the first stage of the project (.08), but increased to moderate in the executive and closing stage (varying from .43 to .53). This implies that in the first stage of the project, students' perception of social relatedness is not related in any way to their perception of competence. In the closing stage, all psychological needs are at least moderately associated (.44-.56), indicating that experiences of autonomy, competence, and social relatedness are substantially intertwined.

\section{Situational Interest as a Function of the Underlying Psychological Needs}

The hypothesised model (see Fig. 1) seemed to fit the data reasonably well. The fit indices of the SEM model were: $\chi^{2}(186)=348.17$, IFI $=.90$, RMR $=.07$, RMSEA $=.06, p$-value of close fit $=.07$. The ratio of $\chi^{2} / \mathrm{df}$ was 1.87 , indicating a good model fit according to Byrne (1989). Besides, the point estimation value of the RMSEA indicated a close fit of the model in relation to the degrees of freedom (Browne \& Cudeck, 1993).

Table 1 Pearson Correlations Between Autonomy, Competence, Social Relatedness, and Situational Interest by Measurement Moment $(N=137)$

\begin{tabular}{|c|c|c|c|c|}
\hline & & Autonomy & Competence & Social relatedness \\
\hline \multirow[t]{3}{*}{ Moment 1 (orientation stage) } & Competence & $.22 * *$ & & \\
\hline & Social relatedness & $.23 * *$ & .08 & \\
\hline & Situational interest & $.16^{* *}$ & $.22 *$ & $.52 * *$ \\
\hline \multirow[t]{3}{*}{ Moment 2 (execution stage) } & Competence & $.42 * *$ & & \\
\hline & Social relatedness & $.46^{* *}$ & $.43 * *$ & \\
\hline & Situational interest & $.59 * *$ & $.50 * *$ & $.49 * *$ \\
\hline \multirow[t]{3}{*}{ Moment 3 (execution stage) } & Competence & $.52 * *$ & & \\
\hline & Social relatedness & $.62 * *$ & $.53 * *$ & \\
\hline & Situational interest & $.62 * *$ & $.50 * *$ & $.66^{* *}$ \\
\hline \multirow[t]{3}{*}{ Moment 4 (execution stage) } & Competence & $.46^{* *}$ & & \\
\hline & Social relatedness & $.34 * *$ & $.43 * *$ & \\
\hline & Situational interest & $.48 * *$ & $.46^{* *}$ & $.69 * *$ \\
\hline \multirow[t]{3}{*}{ Moment 5 (closing stage) } & Competence & $.56^{* *}$ & & \\
\hline & Social relatedness & $.50 * *$ & $.44 * *$ & \\
\hline & Situational interest & $.60 * *$ & $.49 * *$ & $.67 * *$ \\
\hline
\end{tabular}

$* p \leq .05 ; * * p \leq .01$ 
Figure 2 shows the variance explained in interest development, and the unique contributions of the psychological needs in explaining interest (taking into account the interest triggered in previous stages of the CSCL project). The amount of variance explained in terms of interest increased after the orientation stage of the project. In the orientation stage, 32 per cent of the variance was explained, which increased to 46 per cent at the start of the executive stage. During the executive and closing stage, $56 \%-67 \%$ of the variance was explained. Once the project groups made their plan of action and started executing their plan, the interest they expressed in the project not only acted as a stable predictor for the next stage, but was also jointly and uniquely influenced by autonomy, competence, and social relatedness.

In all stages, the unique contribution of social relatedness to emerging individual interest was significant, even taking into account the contribution of the other psychological needs and - with exception of the orientation stage - the situational interest of a previous moment. With exception of the orientation stage, autonomy made a significant unique contribution to interest at all measurement moments. Students' experience of competence also contributed unique variance to interest, except at the end of the execution stage. Note that its contribution is the strongest in the closing stage when students are engaged in a presentation of the project to the other groups and the teachers. Interestingly, feeling autonomous did not affect interest in a unique way when starting on the group project. At that time a sense of social relatedness and competence contributed a substantial portion of unique variance to interest. During the executive stage, we notice a high stability in interest. This may be an indication that fulfilled psychological needs in a CSCL environment fosters the development of a maintained topic or situational interest on its' way to emerging individual interest (Hidi \& Renninger, 2006). The significant direct effects of interest measured during the executive and closing stage underscores the assumption that the triggered topic interest gets more and more maintained over time.

Interview Data on the Benefits and Shortcomings of the Instrument

The interview data yielded information on how to interpret the associations between autonomy, competence, and social relatedness in the various stages of the project. The association between these three aspects of self-determination was low to modest in the orientation stage of the project. This finding points in the direction that effort ought to be invested by the students in finding an optimal balance between their different needs. In the orientation stage, students perceived constraints as well as affordances in the learning environment. For example, students reported that they

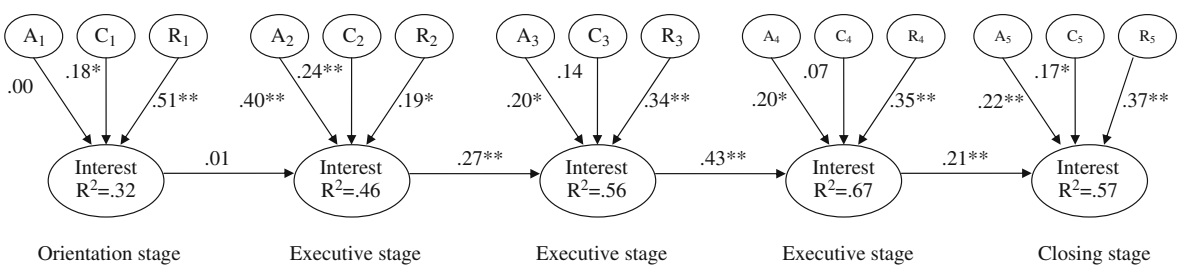

Fig. 2 The ML-solution for the longitudinal SEM model of developing situational interest in a CSCL project. A Autonomy; $C$ Competence; $R$ social Relatedness $* p<.05$. ${ }^{* *} p<.01$. 
needed time to get used to highly intensive and collaborative activities in general and to working in small groups on a long-term project.

It is important to note that most students were highly satisfied with the processoriented feedback provided by the graphical output features (highest rank of the benefits). Some of the groups even added copies of the graphical output to their paper in order to report on the process characteristics of the project. According to both teachers and students, the major benefit of the instrument is that the individual graphical output can be compared with the group output. Students are often suspicious that others in their group are not investing the necessary effort in the project, because they are not interested. Observation of one's own developing interest as an indicator of the fulfilment of one's basic psychological needs, and comparisons with those of peers provides relevant information facilitating mutual understanding and discussion of this important aspect of group work. Our students reported that they now had a tool to verify whether or not their engagement was matched in the group. The students interviewed reported responsible behaviour of their group leader, who focused, more than the other group members, on the learning progress of the group and on social aspects that (might) contribute to the quality of the group learning process. The students interviewed argued that almost all group members engaged in reflective thoughts about the ongoing learning processes, in line with the research findings of Phielix, Prins and Kirschner (2010) about group performance in a CSCL context.

The interview data revealed - as the highest rank among the shortcomings - that students' collaboration is far from optimal in the first stages of the project (also see Vedder \& Veendrick, 2003). Real collaborative group activities are seldom in that stage of the project. Once the 'return on investment' of the project becomes visible or discernible to students, the balance between autonomy, competence, and relatedness becomes optimised, resulting in an equilibrium that fosters interest, engagement, and the development of competencies. At the end of the CSCL project, teachers and students agreed that the quality of the learning process was substantially enhanced if teachers explicitly utilised the information supplied by the assessment tool during the whole course of the project and focused the discussions within the small group on the ongoing learning processes as well as on the students' developing interest (second highest rank in the list of shortcomings). Students' commitment to use the on-line assessment tool, to discuss the results within their group, and to reflect on their project cut down substantially, when teachers forgot to consult the Quality of Working in Groups Instrument data and to provide feedback on the group processes and progress. Some students complained that their teachers/coaches had not answered the questions they communicated to them via the interface of the program.

\section{Conclusion and Discussion}

We began this article with the remark that educational practice is handicapped by a lack of instruments that register students' feelings of disconnection and lack of interest, based on their psychological needs. We also noted that attempts to study students' psychological needs, in close connection with their developing interest, are 
rare. The paper-and-pencil version of the Quality of Working in Groups Instrument was adapted in such a way that students in vocational school could use it electronically, during a CSCL project of a self-chosen project, whenever they wanted to gain information about their own, and their group's developing interest in the project. First, we examined the reliability and validity of the electronic version of the Quality of Working in Groups Instrument. Our data confirmed the reliability and internal validity to measure the basic psychological needs for competence, autonomy, and social relatedness, as well as interest as an experiential state. Second, we looked at the interrelationships between the psychological needs. As expected, inspection of the patterns of correlations between autonomy, competence, and social relatedness revealed that autonomy is associated with both competence and social relatedness in all stages of the project. However, the correlations between autonomy on the one hand and competence and social relatedness on the other are rather modest in the orientation stage (.22 and .23), but an increase is noted in the executive stage (.34-.62). In the executive and closing stages, all psychological needs are at least moderately associated. Third, we examined whether expressed interest in the group project functions as a signal that the students' basic psychological needs are in balance. At the start of the project (i.e. the orientation stage), 32 per cent of the variance in interest was explained by the psychological needs. In the later stages, (more than) half of the variance in interest in the group project was determined by the student's need satisfaction. In other words, when students express low interest in a group learning project it is advisable that teachers/coaches, or the students themselves, take a closer look at the reasons why their psychological needs are not satisfied, because these needs act as the underlying reason interest does or does not develop further. Fourth, data from the semi-structured group interviews on the experiences of teachers and students during the course revealed that the electronic version of the Quality of Working in Groups Instrument enhances students' reflection about and understanding in the ongoing (social) learning process. However, this benefit is conditionally bound to the explicit use of the Quality of Working in Groups Instrument data by the coaches during all the stages of the group learning project. The added value diminished, when teachers neglected using the interface provided by the program and did not answer the students' questions and/or reflections about the group processes and progress.

The significance of this study for our ongoing research project into the monitoring and coaching process is manifold. Students' assessment of the conditions for learning in terms of their perception of autonomy, competence, and social relatedness seems to be a good predictor of their emerging individual interest. This is in line with earlier findings in vocational education (Minnaert, Boekaerts, De Brabander, 2007) and in higher education (see Boekaerts \& Minnaert, 2003). We learned from the (interview) data that vocational students' interest in a group project, which lasts a long time, is largely based on their perception of social relatedness in the group. Perceived competence to design a plan of action and to effectuate the plan contributes to situational interest, particularly in the orientation stage, at the beginning of the execution stage, and in the closing stage. After the orientation stage, perceived autonomy to realise the plan of action and to prepare the final product occupies a more important position as a predictor of interest in the project. 
We believe that the electronic version of the Quality of Working in Groups Instrument allows students and their coaches to inspect the waxing and waning of students' basic psychological needs and interest over time. Inviting students to inspect the coloured curves that depict various aspects of their interaction with the environment and encouraging them to reflect on the quality of the learning process is a powerful way of confronting them with their perception of the constraints and affordances of the learning environment. The computerised version of the questionnaire also allows students to inspect how their peers perceive the quality of the learning environment and how interested they are in the group project. The process-oriented, graphical output features were often subject to within-group discussions. We believe that this kind of information may add to the growth of competencies at the project groups' level, the students' level, and at the teachers' level, by directing individual and group reflection to the strengths and weaknesses of group learning. As such, these discussions could highlight important motivational, social, and discourse processes such as effort avoidance, goal orientations, social competencies, group leadership, elaborating ideas, and posing queries. At the individual level, students' metacognitive awareness and skills about the core constraints and affordances in co-operative and independent learning might increase by a longitudinal, deliberate, and mindful use of this on-line assessment instrument. Although attempts to focus on self-regulation and metacognition in CSCL or technology-based learning environments are scarce in the literature (see also Vauras et al. 2003), more emphasis should be put into the interplay between motivational, social, metacognitive and cognitive processes in technology enhanced learning environments (Alexander \& Wade, 2000). Emphasis on the catching and holding components in situational interest are of added value not only to disentangle the triggering effect of situational interest, but also to identify the empowering effect promoting personal engagement enabling vocational students to maintain their interest and goals (Lewalter \& Krapp, 2004; Mitchell, 1993; Schraw \& Lehman, 2001).

An additional benefit of the electronic version is the detailed information available to the students' teachers. Information about students' developing interest in the group project allows teachers to monitor their coaching to those aspects of the learning episodes that are still problematic for their students. It allows teachers to adapt to the task demands, provide appropriate scaffolding to increase competence, give process-oriented feedback, or change the group composition when they observe that there are obstacles for developing secure and satisfying relations with their peers (see also Phielix, Prins \& Kirschner, 2010). Unfortunately, the interviews with students and teachers revealed that teachers did not always use the available information to encourage students to focus on those aspects of the learning process that might increase the quality of group engagement. As argued previously, the Quality of Working in Groups Instrument is in itself not sufficient or effective to enhance the group learning experience or to prevent problems in the context of collaborative group work. Such an instrument has to be embedded within an educational organisation, where students and teachers take up their new roles.

In sum, coaches ought to be sensitive when a decline in interest occurs within the process of a collaborative group project. This decline predicts a lesser quality of collaboration. The most influencing factor throughout the different project stages is social relatedness. Hence, group cohesion, shared responsibility, and reciprocal relationships are of utmost importance when coaching a group project in vocational 
education. If society calls for employees being able to work in teams, education should explicitly focus on 'learning to work' as teams. In this perspective, students should act as responsible learners, monitoring their progress and reflecting on it, and teachers should act as mindful coaches, encouraging their students to monitor the quality of working in groups and of workplace learning. In line with the plea of Debnath, Tandon and Pointer (2007), it is agreed upon that more powerful (computer supported) learning and coaching environments in the area of commerce and administration education should be designed and implemented.

Open Access This article is distributed under the terms of the Creative Commons Attribution Noncommercial License which permits any noncommercial use, distribution, and reproduction in any medium, provided the original author(s) and source are credited.

\section{Appendix}

Table 2

1. Right now, I am interested in our projecxt

2. I feel capable of doing the project

3. Right now, the team spirit is high

4. We can decide ourselves what we want to do

5. I encourage group members to invest effort

6. Right now, I am enjoying working on our project

7. I have access to the necessary skills to do the project

8. I enjoy being a group member

9. This project allows enough room for initiative

10. I am concerned about whether all group members will learn from the project
0000000 Right now, I would prefer to work on another project

000000 I don't feel capable of doing the project

0000000 Right now, we have trouble working as a team

0000000 We cannot decide ourselves what we want to do

0000000 All group members must decide for themselves whether or not they invest effort

0000000 Right now, I am bored with our project

0000000 I do not have access to the necessary skills

0000000 I would prefer to work in another group

๑०००००० This project does not allow room for initiative

0000000 Whether or not others learn from the project is their own concern

\section{References}

Alexander, P., \& Wade, S. E. (2000). Contexts that promote interest, self-determination, and learning: Lasting impressions and lingering questions. Computers in Human Behavior, 16, 349-358.

Anderson, C. W. (1994, April). Engagement in explanation and design in middle school science. Paper presented at the annual meeting of the American Educational Research Association, New Orleans, USA.

Bennett, N., \& Dunne, E. (1991). The nature and quality of talk in cooperative classroom groups. Learning and Instruction, 1, 103-118.

Boekaerts, M. (1997). Self-regulated learning: A new concept embraced by researchers, policy makers, educators, teachers, and students. Learning and Instruction, 7, 161-186. 
Boekaerts, M., \& Minnaert, A. (2003). Assessment of students' feelings of autonomy, competence, and social relatedness: A new approach to measuring the quality of the learning process through self- and peer assessment. In M. Segers, F. Dochy, \& E. Cascallar (Eds.), Optimising new modes of assessment: In search of qualities and standards (pp. 225-246). Dordrecht: Kluwer Academic Publishers.

Browne, M. W., \& Cudeck, R. (1993). Alternative ways of assessing model fit. In K. A. Bollen \& J. S. Long (Eds.), Testing structural equation models (pp. 136-162). Newbury Park: Sage Publications.

Byrne, B. (1989). Multigroup comparisons and the assumptions of equivalent construct validity across groups: Methodological and substantive issues. Multivariate Behavioral Research, 24, 503-523.

Cho, H., Stefanone, M., \& Gray, G. (2002). Social information sharing in a CSCL community. In G. Stahl (Ed.), Computer support for collaborative learning: Foundations for a CSCL community (pp. 43-50). Hillsdale, NJ: Erlbaum.

Connell, J. P., \& Wellborn, J. G. (1991). Competence, autonomy, and relatedness: A motivational analysis of self-system processes. In M. R. Gunnar \& L. A. Sroufe (Eds.), Self processes and development. The Minnesota symposia on child psychology Vol. 23 (pp. 43-77). Hillsdale, NJ: Lawrence Erlbaum.

Cortina, J. M. (1993). What is coefficient alpha? An examination of theory and application. The Journal of Applied Psychology, 78, 98-104.

Debnath, S. C., Tandon, S., \& Pointer, L. V. (2007). Designing business school courses to promote student motivation: An application of the Job Characteristics Model. Journal of Management Education, 31, 812-831.

Deci, E. L., \& Ryan, R. M. (1985). Intrinsic motivation and self-determination in human behavior. New York: Plenum.

Deci, E. L., Vallerand, R. J., Pelletier, L. G., \& Ryan, R. M. (1991). Motivation and education: The selfdetermination perspective. Educational Psychologist, 26, 325-346.

Dillenbourg, P., \& Traum, D. (1999). Does a shared screen make a shared solution? In C. Hoadley \& J. Roschelle (Eds.), Computer support for collaborative learning (pp. 127-135). Palo Alto, CA: Stanford University.

Ewing, J., \& Miller, D. (2002). A framework for evaluating computer supported collaborative learning. Educational Technology \& Society, 5, 112-118.

Grolnick, W. S., \& Ryan, R. M. (1989). Parent styles associated with children's self-regulation and competence in school. Journal of Education \& Psychology, 81, 43-54.

Hidi, S., \& Renninger, K. A. (2006). The four-phase model of interest development. Educational Psychologist, 41, 111-127.

Järvelä, S., Bonk, C. J., Lehtinen, E., \& Lehti, S. (1999). A theoretical analysis of social interactions in computer-based learning environments: Evidence for reciprocal understandings. Journal of Educational Computing Research, 21, 359-384.

Johnson, D. W., \& Johnson, R. T. (2009). An educational psychology success story: Social interdependence theory and cooperative learning. Educational Researcher, 38, 365-379.

King, A. (1998). Transactive peer tutoring: Distributing cognition and metacognition. Educational Psychology Review, 10, 54-74.

Koschmann, T., Hall, R., \& Miyake, N. (2002). CSCL 2: Carrying forward the conversation. Mahwah: Erlbaum.

Krapp, A. (1999). Interest, motivation and learning: An educational-psychological perspective. European Journal of Psychology of Education, 14, 23-40.

Krapp, A. (2002). An educational-psychological theory of interest and its relation to self-determination theory. In E. L. Deci \& R. M. Ryan (Eds.), The handbook of self-determination research (pp. 405427). Rochester: University of Rochester Press.

Lehtinen, E. (2003). Computer-supported collaborative learning: An approach to powerful learning environments. In E. De Corte, L. Verschaffel, N. Entwistle, \& J. van Merriënboer (Eds.), Powerful learning environments: unravelling basic components and dimensions (pp. 35-53). Amsterdam: Elsevier Science.

Lewalter, D., \& Krapp, A. (2004). The role of contextual conditions of vocational education for motivational orientations and emotional experiences. European Psychologist, 9, 210-221.

Lienert, G. A., \& Raatz, U. (1994). Testaufbau und Testanalyse [test construction and test analysis]. Weinheim: Beltz, Psychologie Verlags Union.

Lindblom-Ylänne, S., \& Pihlajamaki, H. (2003). Can a collaborative network environment enhance essaywriting processes? British Journal of Educational Technology, 34, 17-30.

Martens, R., Bastiaens, T., \& Kirschner, P. A. (2007). New learning design in distance education: The impact on student perception and motivation. Distance Education, 28, 81-91.

Minnaert, A., Boekaerts, M., \& De Brabander, C. (2007). Autonomy, competence, and social relatedness in task interest within project-based education. Psychological Reports, 101, 574-586. 
Minnaert, A., \& Vermunt, J. D. (2006). 25 years of educational psychology in the Netherlands and in Flanders during 1980 till 2005. Pedagogische Studiën, 83, 260-277.

Mitchell, M. (1993). Situational interest: Its multifaceted structure in the secondary school mathematics classroom. Journal of Educational Psychology, 85, 424-436.

Pea, R. D. (1994). Seeing what we build together: Distributed multimedia learning environments for transformative communications. Journal of the Learning Sciences, 3, 283-298.

Phielix, C., Prins, F. J., \& Kirschner, P. A. (2010). Awareness of group performance in a CSCL environment: Effects of peer feedback and reflection. Computers in Human Behavior, 26, 151-161.

Renninger, K. A., Hidi, S., \& Krapp, A. (1992). The role of interest in learning and development. Hillsdale: Lawrence Erlbaum.

Ryan, R. M., \& Deci, E. L. (2000). Self-determination theory and the facilitation of intrinsic motivation, social development, and well-being. The American Psychologist, 55, 68-78.

Schiefele, U. (1991). Interest, learning, and motivation. Educational Psychologist, 26, 299-323.

Schiefele, U. (2001). The role of interest in motivation and learning. In J. M. Collis \& S. Messick (Eds.), Intelligence and personality: Bridging the gap in theory and measurement (pp. 163-194). Mahwah: Erlbaum.

Schraw, G., \& Lehman, S. (2001). Situational interest: A review of the literature and directions for future research. Educational Psychology Review, 13, 23-52.

Sluijsmans, D. M. A., \& Strijbos, J. W. (2010). Flexible peer assessment formats to acknowledge individual contributions during (web-based) collaborative learning. In B. Ertl (Ed.), E-collaborative knowledge construction: Learning from computer-supported and virtual environments (pp. 139-160). Hershey: Information Science Reference.

Vauras, M., Iiskala, T., Kajamies, A., Kinnunen, R., \& Lehtinen, E. (2003). Shared-regulation and motivation of collaborating peers: A case analysis. Psychologia: an International Journal of Psychology of the Orient, 46, 19-37.

Vedder, P., \& Veendrick, A. (2003). The role of the task and reward structure in cooperative learning. Scandinavian Journal of Educational Research, 47, 529-542.

Virtanen, A., Tynjälä, P., \& Collin, K. (2009). Characteristics of workplace learning among Finnish vocational students. Vocations and Learning, 2, 153-175.

Vuorela, M., \& Nummenmaa, L. (2004). How undergraduate students meet a new learning environment? Computers in Human Behavior, 20, 763-777.

Alexander Minnaert is full professor of Special Needs Education and Educational Sciences at the University of Groningen, The Netherlands. He received his Ph.D. in Educational and School Psychology at the University of Leuven, Belgium. His research interests are motivation, emotion, self-regulation, learning (disabilities), and intervention studies on social emotional, motivational and cognitive issues in primary, secondary (vocational), and higher education. He is EARLI SIG coordinator in the area of motivation and emotion.

Monique Boekaerts is full professor at the Centre for the Study of Education and Instruction, Leiden University, The Netherlands. She received her Ph.D. in Educational Psychology at Tiburg University, The Netherlands. She was president of various international scientific organisations (e.g. EARLI, IAAP, IAE) and member of various national scientific organisations (NWO, PROO). Her research interests are teaching and learning, self-regulated learning, motivation, emotion, stress and coping.

Cornelis de Brabander is assistant professor at the Centre for the Study of Education and Instruction, Leiden University, The Netherlands. He received his Ph.D. in Social and Behavioural Sciences at Leiden University, The Netherlands. His interest areas are personal epistemology and efficacy expectancies, but also self-responsible learning, computer aided respectively managed instruction, and the development of an online instrument to monitor self-responsible study groups.

Marie-Christine Opdenakker obtained a Rosalind Franklin fellowship (tenure track) and is appointed as assistant professor in Educational Sciences at the University of Groningen. She received her Ph.D. in Educational Sciences at the University of Leuven, Belgium. Her main research focus is the effectiveness of teachers and schools on student outcomes: in particular teacher-student interaction in relation to the development of student motivation, self-regulation, and methodological issues concerning educational effectiveness research. 